\title{
Standardised module evaluation surveys in UK higher education: establishing students’ perspectives
}

\author{
Christopher Wiley
}

University of Surrey, UK

Address (permanent address of corresponding author): University of Surrey, Guildford, Surrey GU2 7XH UK

[Affiliation at which research was conducted: City University London, Northampton Square, London EC1V 0HB UK]

Telephone: +44 (0) 1483686513

E-mail address (corresponding author): c.wiley@surrey.ac.uk

Twitter: @Chris_Wiley

Acknowledgements: The author wishes to thank all the student representatives who participated in this study, as well as his supervisor for this research and the anonymous peer reviewers for Studies in Educational Evaluation.

Declaration of Interest statement: The author declares no potential conflicts of interest with respect to the research, authorship and/or possible publication of this article. 


\title{
Standardised module evaluation surveys in UK higher education: establishing students’ perspectives
}

\begin{abstract}
Standardised module evaluation surveys have recently been implemented or extensively redesigned at many different HEIs across the UK in response to an evolving national context, notwithstanding a body of scholarship that has called student evaluation of teaching (SET) into question. Through a focussed single-institution study, this mixed-methods research fills a notable gap in the current literature in establishing students' perspectives on standardised module evaluation by means of a paper-based questionnaire. Its participants $(\mathrm{N}=40)$ recognised some general advantages of a university-wide system, such as facilitating comparison between different modules; but they also acknowledged several shortcomings relating to its lack of sensitivity to individual module contexts and schedules, yielding the overall view that standardised surveys are only partially effective as a means of teaching evaluation. The conclusion considers the wider implications of these distinctive findings, and suggests that the perceived limitations of SET point to the need to triangulate its results with data obtained through alternative evaluation mechanisms.
\end{abstract}

Keywords: higher education; student evaluation of teaching (SET); module evaluation; teaching enhancement; teaching recognition; students' perspectives

Highlights:

- Students perceive standardised SET as an only partly effective measure of teaching 
- The standardised format limits SET's applicability to specific teaching contexts

- A single schedule for SET may not align adequately with the teaching delivery

- Standardisation of SET may negatively affect student engagement and response rates

- Care should be exercised over interpreting the results of SET in isolation 
'Despite the common disparagement of student ratings of teachers, they can be highly reliable [...] and relatively immune from biases of various kinds. Students can readily tell the difference between teachers they like and teachers who they think are good teachers [...] These observations are based on the use of thoroughly developed and tested feedback questionnaires. However, in the UK almost all such questionnaires are "home-grown" and are likely to be of doubtful reliability and open to all kinds of biases.’

(Gibbs 2010, 27)

\section{Introduction}

UK higher education has lately witnessed the dawn of an age of unprecedented accountability in relation to the quality of teaching provision (Murray and Smith 2013). Indicators of this shift include the increasing weight placed on nationwide student polls such as the National Student Survey (NSS) and Postgraduate Taught Experience Survey (PTES); the importance currently accorded to a given institution's place in the national league tables, which use data from the NSS; and the regulated publication of Key Information Sets (KIS) incorporating detailed programme-level information on teaching as of 2013-14. The advent of tuition fees, and their escalation to $£ 9,000$ per annum for undergraduate degrees in 2012 (also mirrored in increases to postgraduate fees), has understandably led students to seek value for money in a more consumerist environment; this is reflected in the number of student appeals and complaints received by universities, which has risen year on year to exceed the 20,000 mark by 2012-13 (Abrams 2014). Most recently, the present government’s 2015 manifesto pledge to introduce a Teaching Excellence Framework (TEF) to higher education (Johnson 2015) has reasserted the centrality of teaching quality within institutional agendas nationally. A central proposal of the subsequent White Paper (BIS 2016), the TEF is currently in its third year of implementation at institutional level across the UK, as well as being piloted at subject level at 50 different providers in 2017-18. The evolving national context has brought about the need, inter alia, for higher education institutions (HEIs) 
to develop systematic instruments for internally monitoring students' satisfaction with the effectiveness of the teaching they receive (Smith and Morris 2011; Murray and Smith 2013).

The proliferation of student module evaluation surveys at HEIs across the UK in recent years may therefore be understood as a trend that has emerged in response to changes in the national sector. In some cases, these standardised surveys have represented the consolidation, and often the extensive redesign, of long-standing institution-wide evaluation practices; others have seen the centralisation and implementation of new systems altogether (Smith and Morris 2011; Murray and Smith 2013). The current UK climate therefore offers a distinctive example of the wider international phenomenon of student evaluation of teaching (SET), prompted by specific governmental drivers for strategic policy change.

The potential problem raised by the surveys under scrutiny in this article is elegantly summarised by Gibbs in the above epigraph: unlike international initiatives such as the Student Evaluation of Educational Quality (SEEQ) and National Survey of Student Engagement (NSSE) in North America, or the Course Experience Questionnaire (CEQ) in Australia, the student surveys implemented at module level in the UK are standardised only across their respective HEI, being particular to that institution rather than adopting a nationally-recognised format (Gibbs 2010; Smith and Morris 2011; Murray and Smith 2013). Typically they are completed by students on a module by module basis (albeit often supplemented by annual internal surveys to measure satisfaction at programme level), and capture information about individual lecturers and their teaching in addition to aspects of module content and delivery (Murray and Smith 2013). They are invariably managed centrally within an institution and delivered according to a single schedule coincident with the termly teaching cycle, 
and they may be delivered in paper-based format and/or online (Smith and Morris 2011). Standardisation across an individual HEI is an inevitable part of developing a sustainable structure for such systems, given the sheer volume of administration created by surveying students on this scale. They function to promote equity across all teaching staff, each of whom will be assessed according to the same principles (even if the results may be interpreted differently at the localised level of individual departments and line-managerial structures), and they represent a formal mechanism for periodically gathering data from all taught students to inform activities such as staff annual appraisals and promotions. There are, then, clearly many compelling advantages to maintaining robust quality assurance processes of this nature.

The scholarly literature on student surveys is by no means uniformly critical. The SEEQ (Marsh 1982) has been comprehensively researched and endorsed for validity, reliability and stability across many years of extensive use in the US (Marsh and Hocevar 1991; Marsh and Roche 1997), as well as having been trialled for deployment in the UK (Coffey and Gibbs 2001); the Australian CEQ (Ramsden 1991) has likewise withstood rigorous and widespread scrutiny. Marsh’s (1987) findings with respect to SET have more recently been confirmed by multiple studies on both sides of the Atlantic, which have continued to demonstrate that student feedback questionnaires may indeed be valid, reliable and for the most part bias-free (e.g. Lemos et al. 2011; Wright and Jenkins-Guarnieri 2012; Zhao and Gallant 2012). Gibbs (2010) has mounted a defence on similar grounds, noting that there is an important difference to be observed between students' evaluation of quantifiable parameters such as whether feedback was promptly delivered, and subjective pronouncements on the value of the teaching which may not reflect whether effective learning resulted. Hammonds et al. (2017) have 
explored means by which to optimise interpretation of the findings of student evaluations in order to maximise the consequent enhancement of teaching quality.

In other instances, however, SET has repeatedly been called into question in a body of scholarship from North America, Europe and Australia, primarily on the grounds that its results may reflect many influences other than the teaching itself. Research undertaken in a variety of postsecondary educational contexts has revealed such evaluations to be affected by factors as wide-ranging as the instructor's gender (MacNell, Driscoll, and Hunt 2015; Wagner, Rieger, and Voorvelt 2016; Boring 2017), race (McPherson and Jewell 2007), and fluency of delivery (Carpenter et al. 2013), as well as the effort expended by students on the course (Darby 2007; Stroebe 2016). Several studies have identified a range of additional circumstantial characteristics that influence SET results, with more favourable ratings tending to be received by elective modules (and those that align with students' prior interests) rather than compulsory ones, those with smaller class sizes, and those delivered in more advanced years of an undergraduate course as well as on postgraduate programmes (e.g. Marsh 1984; Johnson, Narayanan, and Sawaya 2013; Nargundkar and Shrikhande 2014). Even offering chocolate to students prior to completing the survey has been shown to generate more positive results (Youmans and Jee 2007). Extensive research conducted by Carrell and West (2010) found that teaching evaluation favours those professors who achieve good immediate student performance (perhaps because they teach narrowly to the assessment) over those who produce better long-term performance in subsequent courses. Uttl, White, and Gonzalez (2017) revisited the findings of previous studies, ostensibly sympathetic to SET, to reveal no significant correlation between student learning and teaching delivered by instructors with high ratings. Stark and Freishtat (2014) argued for the discounting of SET scores as the primary measure of teaching 
quality on statistical grounds, while Boysen (2017) drew attention to teachers’ tendencies to over-interpret results that are not statistically meaningful. Oon, Spencer, and Kam (2017) have discussed the problems relating to 'home-grown' surveys (such as describes many in use at UK HEIs) rarely having been given adequate psychometric assessment, thereby potentially compromising the accuracy of their results. Feistauer and Richter (2017) uncovered both reliability and variance in SET across a three-year study; and even Remedios and Lieberman (2008), whose research pointed towards quality of teaching, student engagement and enjoyment of teaching as the principal determining variables, conceded that student grades and workload are nonetheless contributors.

Identifying student perspectives on module evaluation is therefore both necessary and timely since, to the best of my knowledge, little academic attention has hitherto been devoted to interrogation of the matter. This is the case despite widespread recognition of the importance of students' motivation to engage with formal SET processes as a means of bringing about future enhancements to teaching quality (Chen and Hoshower 2003; Nulty 2008; Smith and Morris 2011; Hammonds et al. 2017), to the extent that their perceptions of the worth of such evaluations may influence the ratings they give (Spooren and Christiaens 2017). One notable exception is Winchester and Winchester (2012), who explored seven students’ views of a weekly diagnostic tool introduced to certain modules as a complement to standard evaluation methods; broadly similar issues are also touched upon in a small handful of other studies (e.g. Onwuegbuzie et al. 2007; Edström 2008; Huxham et al. 2008; Smith and Morris 2011). This current imbalance in the pedagogical literature seems curious when students are also the target population for these surveys, and seems to presuppose the extent to 
which teaching evaluation genuinely benefits its primary stakeholders. One of the intentions of the present study is to start to address this scholarly oversight.

\section{Research Questions}

This research seeks to establish students' perspectives on module evaluation surveys and their standardisation. It proceeds by means of a focussed single-institution study, based on a student questionnaire $(\mathrm{N}=40)$ conducted at a major UK university. The key research questions, which map directly on to the below section presenting the findings, are as follows:

- RQ1: What are the students' perceptions of the advantages and disadvantages of a standardised institution-wide module evaluation survey?

- RQ2: What are their views on the extent to which such a process is effective as a means of teaching recognition and enhancement?

- RQ3: What improved or alternative evaluation instruments might they suggest be hypothetically used for this purpose?

Every endeavour has been undertaken to ensure that the focus of discussion falls not on those findings likely to be applicable exclusively to the institution at which this research was conducted, but on those that speak to the general principles underpinning standardised module evaluation surveys. While the following study is best considered an exploratory pilot intended to lay the foundations for more extensive research, the critique of SET it offers is nonetheless anticipated to yield broader implications of relevance to other HEIs in the UK if not also beyond. Reciprocally, the student perspectives it identifies within a single institutional context will doubtless be of wider inter/national interest to educational researchers, teachers, administrators and policymakers alike. The distinctive focus of this study on the views of the students themselves 
generates strengths as well as limitations for research, opening up rich and fruitful avenues for future scholarship in relation to existing knowledge on SET.

\section{Method}

The study was conducted at an inner city UK university at which a paper-based standardised module evaluation system had been introduced two years previously for all undergraduate and postgraduate teaching across its six schools (referring in this context to a group of cognate academic departments under the leadership of a Dean).

Consciously modelled on the NSS and PTES, it comprises eight 5-point Likert scale questions together with two free-text questions. Students are asked to complete the survey anonymously during the last or penultimate lecture of the corresponding module (but before the final examination or coursework assessment), with separate forms filled in for each member of staff who contributed to the teaching. Individual module scores and feedback are sent to the lecturer(s) for response, and discussed at staff-student liaison committee meetings. Modules whose average overall satisfaction lies below 3.5 out of 5 are regarded as being in need of further exploration to identify developmental actions and to provide additional support going forward, and summaries are reported periodically to the University Senate.

For the purposes of this research, students’ perceptions of standardised module evaluation were established using a paper-based questionnaire completed voluntarily by 40 active student representatives (excluding one respondent who opted out of the study, discussed below) by means of a survey. This methodology was employed to extend the scope of the research significantly beyond that realistically possible using interviews or focus groups. 


\section{The questionnaire}

The questionnaire used for this study (reproduced in the Appendix) comprised 18 questions mapped directly on to the research questions articulated above. Its principal aim was to establish the student voice in relation to the standardised nature of the module evaluation system: advantages and disadvantages (Q9-Q10, Q7), its effectiveness as an instrument for teaching evaluation and recognition (Q8, Q14) and the extent to which a standardised process nonetheless has the capacity to address specific module contexts (Q11-Q12). Two additional questions explored students’ views on possible alternative mechanisms by which teaching quality might be measured (Q15-Q16).

Both the questionnaire design and the below discussion of findings have been underpinned by existing literature in the field. One source that proved particularly instructive was Smith and Morris (2011), which explored issues including the need to undertake SET in advance of the end of a module (rather than at the end, where such surveys are predominantly run in the UK) if timely corrective action is to be taken, as well as the danger that students may not be adequately engaged with the process to begin with, since changes made in light of feedback received may not be sufficiently apparent or may be implemented too late to improve their educational experience substantively. These points directly prompted the inclusion of questions on students' awareness of changes introduced on account of their responses (Q6) and on their views regarding the optimal schedule for evaluating the teaching (Q13), in order to speak to the extent to which standardised module evaluation facilitates teaching enhancement in practice. Another study that informed aspects of the questionnaire's content was that by Porter, Whitcomb, and Weitzer (2004), who identified that multiple surveys, especially when administered in close succession, can lead to reduced engagement, lower response 
rates and survey fatigue. A final pair of questions (Q17-Q18) therefore sought to assess the risk of over-surveying associated with a standardised system, in which students are presented with the same set of survey questions for every module as well as for each teacher within a module.

With the exception of Q1-Q5, whose purpose was to establish background information about the participants and their knowledge of the institutional module evaluation system, all questions are edited into the below discussion of findings. An empirical mixed-methods (primarily qualitative) approach was adopted, utilising a range of 5-point Likert scale, tickbox and free-text responses. Not all participants supplied answers to every question (and some may not have been applicable to them), hence the number of responses to a particular question, $n$, is given below alongside each associated finding (answers of ‘n/a’, 'n.a.', ‘?’, and ‘-’ being regarded as nonresponses); however, all responses received were valid in that, with only one exception, all made attempts to answer both the quantitative and free-text sections. Analysis of the quantitative data garnered from the tickbox questions included calculation of the percentages of responses in each of the prescribed categories (to the nearest whole number), and, in the case of the Likert scales, of mean averages and standard deviations (to 1dp); detailed breakdowns of the data by respondents' year of study and gender are provided in Table 1. The free-text qualitative material was subjected to thematic analysis to determine the key themes that emerged, as well as the number of participants who shared them; the number of words per response (words/response) has also been calculated (to 1dp) for each individual question (see Table 2 for a fuller breakdown). Illustrative responses have been quoted by way of providing representative evidence in support of interpretations of the data. Since all participants were assured that the information they contributed would be kept anonymous, they are here identified 
parenthetically only by the unique number assigned consecutively to their questionnaire paper (hence 'S1' refers to 'Student 1').

\section{The respondents}

In line with previous studies (e.g. Edström 2008), this research specifically recruited active student representatives as participants. The term 'student representatives' here refers to students elected by their peers to represent them at programme, school or university level, who are usually self-nominated and self-selecting although formal elections may take place if desired. Typically up to one student per programme per year acts in this capacity, selected from within their respective cohorts, and they form part of the overall student government body under the leadership of the Students' Union. Their principal function is to act as a liaison between student cohorts and academic staff, and to represent the views of one to the other (however, there is no expectation that they will be student leaders per se). The responses they contributed to this study are therefore likely to have been informed by - and to give an accurate reflection of - the broader views of the hundreds of students they collectively represented, thereby substantially expanding its reach beyond the relatively modest sample size. Since one of the key roles of the student representatives is to sit on staff-student liaison committees, their perspectives would have been further informed by their participation in the detailed institutional discussions that routinely explore the results of module evaluation surveys, to which their wider cohorts will not be privy.

Responses to the questionnaire were solicited via the university’s annual internal student representatives conference as well as the termly student experience forum meetings for three of its six constituent schools selected at random. By these means, a total of 58 questionnaires were distributed to student representatives, yielding a response rate of $71 \%$, including one respondent (not counted among the 40 participants, 
i.e. the total number of respondents is 41) whose returned documentation indicated that they had voluntarily opted out of the study without answering any of the questions. While it has not been possible definitively to determine the number of students who were participating in the university's networks of representation - as opposed to those merely representing their cohorts in name only - in the period during which this research was conducted, the distribution of questionnaires via these avenues suggests a reach of well over half of the active student representatives. It is also impossible to determine why a small number of questionnaires were not returned; in all probability, they were distributed to the aforementioned student forums but never actually reached their intended recipients. Hence the set of 40 participants may be considered a substantial proportion of the overall population as well as a high response rate, comfortably in line with social science benchmarks and, in absolute terms, several times larger than the samples used for analogous studies such as Winchester and Winchester (2012) (N=7) and Edström (2008) (N=2 student representatives and 6 teachers). The students were all given reasonable time to fill in the questionnaire to ensure that they had ample opportunity to represent their views fully in the free-text questions, yielding an overall mean average of 12.8 words per response (1dp), a figure that needs to be read in the further context of many of the responses having been single-word answers, others having been excluded as non-responses (see above), and additional comments found on four of the scripts (56 words total) having been discounted as not answering specific questions. Though representativeness of a sample will never be perfect, the robustness and completeness of the collective responses indicates that a larger sample size or a higher response rate would not have resulted in significant additional gains in knowledge. 
A total of 24 female students (60\%) and 15 males (38\%) submitted responses to the questionnaire, including 31 undergraduate students (78\%) and 7 postgraduates (18\%). One student did not disclose any biographical information about themselves under Section A of the survey, while another did not identify as either an undergraduate or a postgraduate. The participants were drawn from a wide range of disciplines across the university including arts, social sciences, informatics, engineering, mathematical sciences, health sciences, and business studies, with five of its six schools represented in varying proportions (for reasons of preserving anonymity, the schools may not be identified in this study; in any case, since some schools comprise a spread of different subjects, the data collected is insufficiently granular to draw meaningful conclusions concerning respondents’ originating disciplines). However, and reflecting the robustness of responses previously mentioned, few strongly discernible patterns were identifiable in the data relating to the biographical information collected, the purpose of which was simply to ensure a diverse spread of people among the community surveyed. Excepting that male respondents gave slightly longer answers to the free-text questions, with an average of 3.8 more words per response compared to females (see Table 2), factors such as gender, discipline, and seniority (e.g. whether the student was in their first year or further along in their programme) did not seem substantively to affect their answers.

[Table 1 near here]

[Table 2 near here] 


\section{Findings}

\section{Advantages and disadvantages of standardised module evaluation (RQ1)}

In answer to Q9, 'what are the advantages of standardised module evaluation?' (n=31; 11.6 words/response), the two principal benefits that the students acknowledged were that it establishes a uniform format across the institution (cited by 7 respondents), and, more specifically, that it facilitates direct comparison of modules within and beyond programmes (cited by a separate 7 respondents). Free-text comments included that 'It is an attempt to get feedback to be more consistent' (S17) and 'the whole university has the same criteria for feedback, which means it will be easier to look at [it] as a whole and how it is performing' (S1). However, standardisation was simultaneously recognised to be problematic, one student writing that it 'Enables [the institution] to compare between courses, but doesn’t show specificities of each course' (S24).

Responses to Q10, ‘Are you aware of any disadvantages of standardised module evaluation?' (n=29; 16.0 words/response), pointed above all else towards this limited sensitivity to the individual context of a programme or discipline, identified by a total of 18 participants (62\% of respondents to this question). Particular issues raised with an institution-wide survey included that 'some points suggested may not apply to all

modules' (S37), 'module-specific items are not present' (S56) and 'Some modules [are] not so "standard"' (S2).

The results of the tickbox Q17, 'Approximately how long in total would you estimate that you spend filling out module evaluation surveys per term?' were as follows: 0-15 minutes (19 responses [49\%]), 15-30 minutes (13 responses [33\%]), 3060 minutes (7 responses [18\%]) $(\mathrm{n}=39)$. Moreover, when asked Q18, 'do you feel that you are under-surveyed, over-surveyed or that the level of surveying is just right?', 20 
students answered 'just right' (53\%) , 11 'under-surveyed' (29\%) and 7 'over-surveyed' (18\%) (n=38) (see Tables 3 and 4 for fuller breakdowns).

[Table 3 near here]

[Table 4 near here]

\section{Effectiveness of standardised module evaluation in recognising and enhancing teaching (RQ2)}

The participants were asked to provide various responses using a 5-point Likert scale (see Table 1). Q8, 'how effective is the standardised module evaluation form in evaluating the modules on your programme?', and Q11, ‘to what extent does standardised module evaluation capture "local context" e.g. information specific to the department, programme or discipline?', yielded averages of 3.6 and 3.2, respectively ( $\mathrm{n}=38$ for both questions).

In answer to Q12, 'what aspects of this "local context” are not captured by module evaluation?' ( $\mathrm{n}=20 ; 8.0$ words/response), one participant stated that its focus on lecture-based teaching - which is typical of much UK higher education - overlooks the ‘student experience with teachers outside lectures’ (S37). Along similar lines, another wrote that 'there is a lot of aftercare that doesn't get highlighted in the feedback forms' (S26), this being a consequence of the standardised schedule. A third noted that evaluation of team-taught modules generates unnecessary duplication, 'even if feedback is non-specific to each tutor' (S23).

The free-text Q7, ‘Are you aware of any problems that may have been experienced with implementing or administering standardised module evaluation on your programme?' (n=22; 10.6 words/response), raised additional shortcomings. Low response rates were specifically mentioned by 5 participants, who observed that this can lead to inaccurate or unrepresentative survey data. A further 4 responses crystallised 
around problems arising from the institution's paper-based method of data collection, including the effect on response rates when students are absent from the classes surveyed. One participant also noted that 'Handwritten comments are identifiable to individual students on small courses’ (S9).

The single issue most often mentioned in connection with the implementation of standardised module evaluation concerned the schedule (cited by 7 respondents), since the survey - like the majority administered at UK HEIs - takes place at the end of classbased teaching but before the assessment cycle has been completed. The institution's practice of collecting data during the final or penultimate lecture of a module was considered to be simultaneously too late to make changes to teaching and too early to capture information about assessments. One participant said that it yields an 'example of some questions being made irrelevant' (S2) since the standardised survey nonetheless solicits information about a module’s assessment and feedback.

The free-text Q13, 'What point in the module would you consider to be the best time to conduct the module evaluation exercise[...]?’, primarily prompted two groups of answers ( $\mathrm{n}=33$; 16.1 words/response). One was that it should be undertaken as late as possible, either at the end of the module (cited by 4 respondents), towards the end (5 respondents), after the final assessment (4 respondents) or after feedback and results have been returned (6 respondents). The other was that a mid-module evaluation should be introduced, either instead of (6 respondents) or as well as (6 respondents) an end-ofmodule counterpart, the reason being that 'if improvements are to be made, this can be done in the last $50 \%$ of the teaching of the module' (S6). In summary, of those who responded to this question, 58\% suggested that module evaluation should occur at or near the completion of the teaching and assessment cycle (as distinct from completion of the lectures), and 36\% that there should be a mid-module evaluation. 
Q6, 'To what extent are you aware of changes made as a result of issues addressed on module evaluations?', produced an average of 3.0 on the 5-point Likert scale ( $\mathrm{n}=39$ ), indicative of neutrality overall (see Table 1$)$. Individuals noted the 'feeling that criticism does not get heard or acted on' (S18) and that module evaluation takes place 'Too late for students to get what needs to be changed' (S16).

\section{Alternative measures of student evaluation of teaching (RQ3)}

Responses to Q14, 'to what extent does module evaluation yield an accurate picture of teaching excellence[...]?', averaged at 3.4 on the 5-point Likert scale $(n=39)$ (see Table 1). The free-text Q15, 'If not through module evaluation, in what other way(s) might teaching excellence be recognised?' (n=25; 10.0 words/response), prompted a total of 13 respondents (52\%) to propose formalised verbal consultations with students such as meetings with personal tutors, discussions at staff-student liaison committees, the establishment of open-door policies or interviews between selected students and a neutral member of staff. One participant suggested that 'Students give deeper feedback verbally than on feedback forms' (S18); another that 'when interviewed[,] people tend to give more info[rmation]' (S55). A further 6 respondents to this question (24\%) mentioned institutional student-led teaching awards, which have lately appeared across the UK, partly as the result of a joint initiative by the Higher Education Academy and the National Union of Students. Other answers included student performance as measured by grades achieved (cited by 4 respondents) and peer observation conducted by other teaching academics (2 respondents).

Q16, 'Could the grades awarded in a given module be used to recognise teaching excellence (yes/no), and why?' (n=34; 14.2 words/response), prompted 18 students to answer 'yes' (53\%) and 16 to answer 'no' (47\%), evidencing a striking lack of consensus on this issue. Only a single reason in favour of the proposal was 
consistently indicated by the participants: that grades reflect the quality of teaching and learning support (cited by 8 respondents). They held that the grade echoes 'how much the teachers help [the] student out' (S37) and that 'If a cohort gets bad marks this suggests a problem with delivery of the module’ (S55).

Those who answered in the negative advanced several arguments in support of their opinion, for instance, that students who do not engage significantly with teaching might nonetheless succeed on the module (cited by 2 respondents), and that there may be significant variation in marking (cited by a separate 2 respondents). One participant observed that 'grading individual modules varies quite wildly (and differently between subjective, essay-based/presentation [assessments] \& objective ones such as statistics)' (S15). However, the point most frequently mentioned was that grades measure students' attainment rather than teachers' ability (9 respondents). Comments included that using students' performance to evaluate teaching would constitute 'unfair representation in some cases with students of varying skills' (S29), and that 'teaching may be unsatisfactory but students may still get good marks due to [their] own efforts + vice versa' (S30).

\section{Discussion}

The student perspectives explored in this research acknowledged some general benefits of standardised module evaluation, in terms of establishing consistency as well as facilitating the comparison of different modules. At the same time, several limitations of an institution-wide system were identified, primarily that it was held not adequately to capture information specific to the individual modules it was used to evaluate. The overall perception yielded was that standardised surveys are only effective as module evaluation up to a point, leading to the distinctive conclusion that a 'home-grown' standardised survey, such as those typically implemented at UK HEIs, may provide 
only a partial impression of teaching effectiveness when considered in isolation. It also confirms the views expressed in the free-text comments concerning the limited capacity of such a survey to take account of the contexts of individual modules.

The extent to which the respondents felt that module evaluation gave an accurate picture of teaching excellence may reflect that the routine use of narrow numerical scales for teaching evaluation typically produces similar scores for each module, thereby affording little scope to distinguish between barely satisfactory teaching and excellent teaching. For example, under the institutional system with which the study participants were familiar, the vast majority of scores lie between 3.5 and 4.5 out of 5 . This suggestion is consonant with the limited variation identified by Denson, Loveday, and Dalton (2010) in respect of a four-point scale used for student course evaluation at one Australian university. It is also in line with the findings of a recent literature review by Gunn and Fisk (2013, 7), foremost among which is the 'lack of articulation around the differences between threshold quality and teaching excellence'.

The findings of this study also called into question the single schedule for standardised module evaluation, on the grounds that it does not enable changes to be implemented in time to improve the experience of the students being surveyed, nor give them the opportunity to respond to the totality of the teaching and assessment on a given module. This presents a danger that students could become disengaged with the module evaluation process, since some of the questions might not seem applicable to them at that particular juncture in the cycle of delivery. The students' perspective, then, is that evaluation is typically conducted at the wrong point(s) in the module, signalling that a different schedule for teaching evaluation might be more effective. Correspondingly, the students may not witness the enhancements or interventions implemented in consequence of their survey responses, since only limited evidence was uncovered by 
this study of their awareness of actions taken as a result of their feedback. This speaks further to the risk, previously suggested by Chen and Hoshower (2003), that students may become disenfranchised if they perceive few direct benefits from participating in module evaluation exercises, as well as to the possibility indicated by McClain, Gulbis, and Hays (2018) that responses to such surveys are more likely to be honest if the students believe that they will be effective in enhancing teaching and benefitting future cohorts.

Low response rates are a well-known problem with course evaluation that has received much discussion in the literature, and inevitably affect the value of the data gathered. Nulty (2008) formulated sliding scales identifying the minimum response rates for given class sizes, at which guide point (but not before) the data theoretically becomes sufficient to yield information representative of the cohort, while James, Schraw, and Kuch (2015) devised a series of equations and tables from which to determine margin of error and statistical validity for this same purpose. Smith and Morris (2011) proposed that a rate of return greater than 50\% was needed to ensure meaningful results. However, that such thresholds are generally attained in the university at which the present study was conducted (the surveys having been systematically undertaken during lectures) suggests the students perceived that even when the number of non-participants was in the minority, the accuracy of the sample and its interpretative significance might nonetheless be compromised. One possible alternative would be to develop an electronic (or hybridised) system. This would ameliorate the aforementioned problem of being able to identify respondents by their handwriting, leading to a potential loss of anonymity that would doubtless influence the nature and scope of the feedback that they felt able to provide. However, there is considerable evidence in the scholarly literature (e.g. Dommeyer et al. 2004; Nulty 
2008; Crews and Curtis 2011; Kember and Ginns 2012; Stowell, Addison, and Smith 2012; Capa-Aydin 2016) that paper-based surveys typically lead to significantly higher levels of student engagement than those conducted online.

A number of other measures were proposed as hypothetical alternatives, including verbal consultation with students, analysis of student grades and peer observation of teaching. The use of student grades to evaluate teaching, in particular, warrants further consideration. While such a measure runs an obvious risk of strategic grade inflation on the part of staff (cf. McPherson and Jewell 2007; Stroebe 2016), the general trend of grades having risen in UK higher education in recent years is so widely recognised that governmental measures have lately been proposed to tackle it, including the possibility of HEIs adopting a Grade Point Average model (BIS, 2016). Analogous performance metrics are already adopted in other contexts: the percentage of 'good honours' degree classes (firsts and upper seconds) is a criterion in two of the three major national league tables. Multiple studies have also identified a relationship between students’ grades (or expected grades) and SET ratings (e.g. Marsh 1984; Isely and Singh 2005; Weinberg, Hashimoto, and Fleisher 2009; Patrick 2011; Johnson, Narayanan, and Sawaya 2013). Several of the participants in the present study further indicated that members of staff could be disadvantaged under such scenarios since there may be no correlation between teaching quality and grades attained.

The possibilities that additional verbal consultation would present for students to provide feedback at more than one point of evaluation per module, perhaps even on a continuous basis, was at least implicit in the participants' endorsement of these alternative mechanisms. Mindful of the potential for survey fatigue, this line of enquiry raises the related matter of whether the typical practice in the UK of delivering one questionnaire for every module already constitutes too great a level of student 
consultation. Since it is standard for such course evaluations to be disaggregated by lecturer in order to capture data unique to individuals, scenarios involving multiple teachers further increase the danger of survey fatigue as well as potentially disadvantaging subjects in which team-teaching is more commonly practised. But, while a minority of respondents felt that the level of institutional surveying was too great, for a substantial majority this activity took up less than 30 minutes per term, and within this specific context, survey fatigue did not therefore present itself as a major concern.

\section{Recommendations}

The findings of this study gives rise to several immediate recommendations, which, while principally relevant to the university at which the research was conducted, are at the same time clearly generalisable to a range of other institutional contexts within the UK and beyond in which course evaluation follows standardised formats, not least given the high level of consonance with many previous studies on SET internationally.

1. While common questions are useful for benchmarking purposes, in light of the recognition by students that a standardised survey alone is not sufficiently sensitive to local contexts, it would greatly benefit from being supplemented by additional programme-specific questions. Such practices have previously been advocated by Smith and Morris (2011), while Kember and Ginns (2012) have provided a comprehensive question bank upon which to draw.

2. Consideration should be given to revising the standardised schedule to take account of the preferences expressed by the participants for different data collection points, namely, the inclusion of an interim (mid-term) evaluation in addition to a final evaluation once the teaching and assessment cycle has been 
completed. Huxham et al. (2008) have called for more widespread recognition of the distinction between formative and summative teaching evaluation, advocating the use of open-question methods for the former instead of a standardised questionnaire, and this may provide an instructive model to adopt. Developing possibilities for modules that follow non-standard schedules to be separately evaluated would also appear to be advantageous.

3. In view of the only limited awareness among participants of actions taken in response to their feedback, there would be great merit in staff responses to the results of module evaluation surveys being routinely and promptly communicated to all students on the associated programme(s). Such an initiative may serve to enhance response rates in the longer term by foregrounding the consequences of engagement with the process and ameliorating any sense that criticism is simply dismissed, as well as doubling as a means of disseminating best practices. Murray and Smith (2013) identified that only one in ten of the UK universities they surveyed communicates the full results of module evaluation exercises to students together with the institutional response, although there was evidently much appetite to do so.

4. Given that problems associated with low response rates were markedly apparent to the participants, it may be prudent to adopt measures to address the points they raised that could lead to disengagement or survey fatigue, such as (in addition to the above) perceived duplication in completing the forms, as well as to ensure that the questionnaires are always administered consistently.

These proposals, borne of the distinctive perspectives resulting from this study, represent an ideal position and bring their own challenges, not least the inevitable increases to the administrative resources that would be required to implement them. 
Revising the standard schedule also raises the very real danger, highlighted by Weinberg, Hashimoto, and Fleisher (2009), that responses to the final module evaluation may be influenced by the grades received by the students rather than reflecting the quality of teaching and the learning that has taken place.

Various studies (e.g. Kember and Ginns 2012; Carpenter et al. 2013) have previously identified the need to establish a range of methods for evaluating teaching in tandem, in order to gain a more rounded picture of its quality and effectiveness; the importance of adopting multiple criteria for SET itself may be traced at least as far back as Marsh’s (1987) foundational research in relation to the multidimensionality of teaching. Huxham et al. (2008) showed that the closed questions of a standardised survey yielded notably different results from 'comparator' methods that used more open questions (including rapid feedback and focus-group interviews), the latter raising a wide spectrum of issues only partly covered by the questionnaire as well as providing a stronger sense of their relative importance and a greater level of specificity. Onwuegbuzie et al. (2007) found that several themes cited repeatedly by nearly 1,000 university students as important markers of effective teaching were unaddressed by the institutional teaching evaluation form. More recently, Linse (2017) has provided a helpful summary of the principal issues involved in interpreting SET findings, together with series of guidelines for institutional assessors. These studies alone highlight the problems associated with over-reliance upon a standardised survey whose results are reviewed in isolation and without due contextualisation.

A number of other mechanisms proposed by the study participants could usefully be considered alongside module evaluation survey data by way of triangulating this information in future assessments of teaching. Student achievement as measured by the grades awarded proved to be a divisive proposal for various reasons, not least that 
(as noted) it might lead to deliberate grade inflation. However, student-led teaching award schemes and peer observation were both viewed more positively as evaluation tools by those respondents who cited them, suggesting that the data generated by such activities might provide instructive counterpoints to module evaluation. Were this additional recommendation to be adopted, it would necessitate the development of more comprehensive, standardised processes than presently exist across many HEIs in respect of instruments such as peer observation of teaching, which would itself benefit from similarly rigorous critique (Smith 2012; Iqbal 2013).

Perhaps the most unexpected finding of this study was the significant appetite for alternative verbal consultations with students. A final recommendation, then, would be the continued cultivation of open and systematic mechanisms by which students may supply oral feedback as a complement to standardised module evaluation itself, whether as part of the processes of triangulation outlined above or, indeed, as a form of interim evaluation. An initiative of this nature might also afford possibilities for dialogue with students that could, in turn, inform the future development of institutional evaluation tools. Moreover, it would enable module evaluation data to become the starting-point of reflection and discussion, rather than the end-point of a process of quality enhancement and institutional review. Via this means, SET results could fruitfully be further considered with students to determine whether they indeed constitute an accurate reflection of their overall views, prior to an institution responding with more formal enhancement or capability action.

\section{Limitations}

Some limitations were apparent in this research, not least that it was constructed as a focussed single-institution study, exploratory in nature. It is, however, extremely improbable that its findings are unique to one HEI, given that similar policies and 
processes have recently been implemented across the UK and that some of its participants will have possessed at least a modest knowledge of the broader national and even international educational contexts. As such, the results and conclusions set out above will likely find resonance elsewhere in the UK postsecondary sector and beyond, suggesting the need for wider research to be conducted to establish students' perceptions of SET within different institutional settings by way of confirming and reinforcing the findings of this study.

Another limitation, common to much educational research in which students are recruited as participants, was that the respondents are likely to have been among the institution's most engaged and active students. Their opinions may therefore reflect a keenness that may not be shared across the entire student population in respect of matters including their willingness to undertake extra enhancement activities such as interviews, or their relative lack of concern with the current level of institutional surveying and the consequent danger of survey fatigue. While they are generally empowered by virtue of their position as active student representatives to express the views of their associated cohorts, in certain very specific respects their responses might not have been reflective of wider student perspectives. Similarly, while students generally lack the expert-level knowledge of module evaluation methodologies that might have inflected some of the opinions presented above, such as a detailed awareness of nuanced strategies for interpreting response rates with respect to statistical validity, student representatives will be among those best versed in these matters by virtue of their active involvement in institutional discussions around the findings of SET exercises. 


\section{Future research}

Future scholarship would benefit from seeking more fully to examine students’ perceptions of the whole concept of teaching evaluation, which, as noted, is underrepresented within existing literature internationally, and would therefore offer considerable opportunity for comparison with previous research, which has with some consistency approached the issue from the standpoint of the institution, policy-makers, and/or teaching staff, examining the design and/or results of SET instruments rather than seeking the opinions of the surveyed. The scope of this small-scale research precluded conducting interviews with students as well as staff in order to triangulate the perspectives derived from the questionnaires, but this would represent one rich means of building on its findings (even within its original context of a single HEI) by enabling further exploration of particular points, such as to identify the extent to which responses might be affected by factors such as gender, discipline, and seniority of the student in a larger study. More comprehensive student consultation could lead ultimately to the development of an institutional module evaluation system sensitive to the specifics of individual module and disciplinary contexts, and this is one area in which studies of this nature therefore yield the potential to make a distinctive, student-facing contribution to research. Such an instrument might seek to incorporate rigorous mid-module and endof-module evaluation exercises as well as maximising the use of open questions, employing a wider numerical scale for quantitative responses to generate greater differentiation between satisfactory and excellent teaching. Subsequent work could also include further investigation of models by which different means of measuring the efficacy of teaching - such as module evaluation, peer observation, measures of student achievement, and semi-structured student interviews - might simultaneously operate and inform each other. 
Finally, mindful of the point of departure for this study, any redesign of module evaluation surveys might usefully make greater consideration of lessons learnt from the widespread success of comprehensively researched programme-level counterparts from North America and Australia. Gibbs (2010) has pointed towards the Student Evaluation of Educational Quality (SEEQ) as a meticulously developed, reliable exemplar, while Kember and Ginns’s (2012) exploration of teaching evaluation is enriched through parallel discussion of the NSS, CEQ and NSSE. Evidently there remains much valuable work still to be undertaken on SET in a range of different areas.

\section{Conclusion}

This study has explored student perspectives in which standardised module evaluation was seen to be only partly effective as a means of measuring and enhancing higher education teaching. Concern was raised over the standardised format for its limited responsiveness to specific contexts, as well as for its adherence to a single schedule that may align imperfectly with a given module’s teaching and assessment pattern. Some indirect evidence was also uncovered to suggest that standardisation may affect student engagement and response rates, since the relevance to individual students of the resulting evaluation exercise is not always apparent. These findings are sufficient to warrant caution over too literal an interpretation of the results of module evaluation in isolation. Rather than prioritising these standardised surveys as the principal metric of a lecturer's teaching quality, it would be advantageous for the information they yield to be suitably contextualised by triangulating it with data obtained via alternative mechanisms. 


\section{Funding}

This research did not receive any specific grant from funding agencies in the public, commercial or not-for-profit sectors.

\section{References}

Abrams, F. 2014. “University complaints by students top 20,000.” BBC News Magazine, June 3. Accessed February 162018. http://www.bbc.co.uk/news/education-27640303

BIS. 2016. Success as a Knowledge Economy: Teaching Excellence, Social Mobility and Student Choice. London: Department for Business, Innovation \& Skills. Accessed February 162018. https://www.gov.uk/government/uploads/system/uploads/attachment_data/file/5 23396/bis-16-265-success-as-a-knowledge-economy.pdf

Boring, A. 2017. “Gender biases in student evaluations of teaching.” Journal of Public Economics 145: 27-41. doi:10.1016/j.jpubeco.2016.11.006

Boysen, G.A. 2017. "Statistical knowledge and the over-interpretation of student evaluations of teaching.” Assessment \& Evaluation in Higher Education 42 (7): 1095-1102. doi:10.1080/02602938.2016.1227958

Capa-Aydin, Y. 2016. "Student evaluation of instruction: comparison between in-class and online methods.” Assessment \& Evaluation in Higher Education 41 (1): 112-126. doi:10.1080/02602938.2014.987106

Carpenter, S.K., Wilford, M.M., Kornell, N., and Mullaney K.M. 2013. “Appearances can be deceiving: instructor fluency increases perceptions of learning without increasing actual learning.” Psychonomic Bulletin \& Review 20: 1350-1356. doi:10.3758/s13423-013-0442-z

Carrell, S., and West, J. 2010. “Does Professor Quality Matter? Evidence from Random Assignment of Students to Professors.” Journal of Political Economy 118 (3): 409-432. doi:10.1086/653808

Chen, Y., and Hoshower, L.B. 2003. "Student Evaluation of Teaching Effectiveness: An assessment of student perception and motivation.” Assessment \& Evaluation in Higher Education 28 (1): 71-88. doi:10.1080/02602930301683 
Coffey, M., and Gibbs, G. 2001. "The Evaluation of the Student Evaluation of Educational Quality Questionnaire (SEEQ) in UK Higher Education.” Assessment \& Evaluation in Higher Education 26 (1): 89-93. doi:10.1080/02602930020022318

Crews, T.B., and Curtis, D.F. 2011. "Online course evaluations: faculty perspective and strategies for improved response rates.” Assessment \& Evaluation in Higher Education 36 (7): 865-878. doi:10.1080/02602938.2010.493970

Darby, J.A. 2007. "Evaluating course evaluations: the need to establish what is being measured.” Assessment \& Evaluation in Higher Education 32 (4): 441-455. doi:10.1080/02602930600898577

Denson, N., Loveday, T., and Dalton, H. 2010. "Student evaluation of courses: what predicts satisfaction?” Higher Education Research \& Development 29 (4): 339356. doi:10.1080/07294360903394466

Dommeyer, C.J., Baum, P., Hanna, R.W., and Chapman, K.S. 2004. “Gathering faculty teaching evaluations by in-class and online surveys: their effects on response rates and evaluations.” Assessment \& Evaluation in Higher Education 29 (5): 611-23. doi:10.1080/02602930410001689171

Edström, K. 2008. “Doing course evaluation as if learning matters most.” Higher Education Research \& Development 27 (2): 95-106. doi:10.1080/07294360701805234

Feistauer, D., and Richter, T. 2017. “How reliable are students’ evaluations of teaching quality? A variance components approach.” Assessment \& Evaluation in Higher Education 42 (8): 1263-1279. doi:10.1080/02602938.2016.1261083

Gibbs, G. 2010. Dimensions of quality. York: The Higher Education Academy. Accessed February 162018. https://www.heacademy.ac.uk/sites/default/files/dimensions_of_quality.pdf

Gunn, V., and Fisk, A. 2013. Considering teaching excellence in higher education: 2007-2013. A literature review since the CHERI report 2007. York: The Higher Education Academy. Accessed February 162018. https://www.heacademy.ac.uk/sites/default/files/resources/TELR_final_acknowl edgements.pdf

Hammonds, F., Mariano, G.J., Ammons, G., and Chambers, S. 2017. “Student evaluations of teaching: Improving teaching quality in higher education.” 
Perspectives: Policy and Practice in Higher Education 21 (1): 26-33. doi:10.1080/13603108.2016.1227388

Huxham, M., Laybourn, P., Cairncross, S., Gray, M., Brown, N., Goldfinch, J., and Earl, S. 2008. "Collecting student feedback: a comparison of questionnaire and other methods.” Assessment \& Evaluation in Higher Education 33 (6): 675-686. doi:10.1080/02602930701773000

Iqbal, I. 2013. “Academics’ resistance to summative peer review of teaching: questionable rewards and the importance of student evaluations.” Teaching in Higher Education 18 (5): 557-569. doi:10.1080/13562517.2013.764863

Isely, P., and Singh, H. 2005. “Do Higher Grades Lead to Favorable Student Evaluations?” The Journal of Economic Education 36 (1): 29-42. doi:10.3200/JECE.36.1.29-42

James, D.E., Schraw, G., and Kuch, F. 2015. "Using the sampling margin of error to assess the interpretative validity of student evaluations of teaching.” Assessment \& Evaluation in Higher Education 40 (8): 1123-1141. doi:10.1080/02602938.2014.972338

Johnson, J. 2015. “Teaching at the heart of the system”, July 1. Accessed February 16 2018. https://www.gov.uk/government/speeches/teaching-at-the-heart-of-thesystem

Johnson, M.D., Narayanan, A., and Sawaya, W.J. 2013. "Effects of Course and Instructor Characteristics on Student Evaluation of Teaching across a College of Engineering.” Journal of Engineering Education 102 (2): 289-318. doi:10.1002/jee.20013

Kember, D., and Ginns, P. 2012. Evaluating Teaching and Learning: A practical handbook for colleges, universities and the scholarship of teaching. Abingdon: Routledge.

Lemos, M.S., Queirós, C., Teixeira, P.M., and Menezes, I. 2011. “Development and validation of a theoretically based, multidimensional questionnaire of students' evaluation of university teaching.” Assessment \& Evaluation in Higher Education 36 (7): 843-864. doi:10.1080/02602938.2010.493969

Linse, A.R. 2017. "Interpreting and using student ratings data: Guidance for faculty serving as administrators and on evaluation committees.” Studies in Educational Evaluation 54: 94-106. doi:10.1016/j.stueduc.2016.12.004 
McClain, L., Gulbis, A., and Hays, D. 2018. "Honesty on student evaluations of teaching: effectiveness, purpose, and timing matter!” Assessment \& Evaluation in Higher Education 43 (3): 369-385. doi:10.1080/02602938.2017.1350828

MacNell, L., Driscoll, A., and Hunt, A.N. 2015. "What’s in a Name: Exposing Gender Bias in Student Ratings of Teaching.” Innovative Higher Education 40 (4): 291303. doi:10.1007/s10755-014-9313-4

McPherson, M.A., and Jewell, R.T. 2007. "Leveling the Playing Field: Should Student Evaluation Scores be Adjusted?” Social Science Quarterly 88 (3): 868-881. doi:10.1111/j.1540-6237.2007.00487.x

Marsh, H.W. 1982. "SEEQ: A reliable, valid, and useful instrument for collecting students' evaluations of university teaching.” British Journal of Educational Psychology 52 (1): 77-95. doi:10.1111/j.2044-8279.1982.tb02505.x

Marsh, H.W. 1984. “Students’ Evaluations of University Teaching: Dimensionality, Reliability, Validity, Potential Biases, and Utility.” Journal of Educational Psychology 76 (5): 707-754. doi:10.1037/0022-0663.76.5.707

Marsh, H.W. 1987. “Students' evaluations of University teaching: Research findings, methodological issues, and directions for future research.” International Journal of Educational Research 11 (3): 253-388. doi:10.1016/0883-0355(87)90001-2

Marsh, H.W., and Hocevar, D. 1991. “Students' evaluations of teaching effectiveness: The stability of mean ratings of the same teachers over a 13-year period.” Teaching and Teacher Education 7 (4): 303-314. doi:10.1016/0742051X(91)90001-6

Marsh, H.W., and Roche, L.A. 1997. “Making students’ evaluations of teaching effectiveness effective: The critical issues of validity, bias, and utility." American Psychologist 52 (11): 1187-1197. doi:10.1037/0003-066X.52.11.1187

Murray, H., and Smith, P. eds. 2013. Closing the loop: Are universities doing enough to act on student feedback from course evaluation surveys? London: Electric Paper.

Nargundkar, S., and Shrikhande, M. 2014. "Norming of Student Evaluations of Instruction: Impact of Noninstructional Factors.” Decision Sciences Journal of Innovative Education 12 (1): 55-72. doi:10.1111/dsji.12023

Nulty, D.D. 2008. “The adequacy of response rates to online and paper surveys: what can be done?” Assessment \& Evaluation in Higher Education 33 (3): 301-314. doi:10.1080/02602930701293231 
Onwuegbuzie, A.J., Witcher, A.E., Collins, K.M.T., Filer, J.D., Wiedmaier, C.D., and Moore, C.W. 2007. “Students’ Perceptions of Characteristics of Effective College Teachers: A Validity Study of a Teaching Evaluation Form Using a Mixed-Methods Analysis.” American Educational Research Journal 44 (1): 113-160. doi:10.3102/0002831206298169

Oon, P.-T., Spencer, B., and Kam, C.C.S. 2017. "Psychometric quality of a student evaluation of teaching survey in higher education.” Assessment \& Evaluation in Higher Education 42 (5): 788-800. doi:10.1080/02602938.2016.1193119

Patrick, C.L. 2011. "Student evaluations of teaching: effects of the Big Five personality traits, grades and the validity hypothesis.” Assessment \& Evaluation in Higher Education 36 (2): 239-249. doi:10.1080/02602930903308258

Porter, S.R., Whitcomb, M.E., and Weitzer, W.H. 2004. "Multiple Surveys of Students and Survey Fatigue.” New Directions for Institutional Research 121: 63-73. doi:10.1002/ir.101

Ramsden, P. 1991. “A performance indicator of teaching quality in higher education: The Course Experience Questionnaire.” Studies in Higher Education 16 (2): 129-150. doi:10.1080/03075079112331382944

Remedios, R., and Lieberman, D.A. 2008. “I liked your course because you taught me well: the influence of grades, workload, expectations and goals on students' evaluations of teaching.” British Educational Research Journal 34 (1): 91-115. doi:10.1080/01411920701492043

Smith, H. 2012. “The unintended consequences of grading teaching.” Teaching in Higher Education 17 (6): 747-754. doi:10.1080/13562517.2012.744437

Smith, P., and Morris, O. eds. 2011. Effective Course Evaluation: The Future for Quality and Standards in Higher Education. London: Electric Paper.

Spooren, P., and Christiaens, W. 2017. "I liked your course because I believe in (the power of) student evaluations of teaching (SET). Students' perceptions of a teaching evaluation process and their relationships with SET scores.” Studies in Educational Evaluation 54: 43-49. doi:10.1016/j.stueduc.2016.12.003

Stark, P.B., and Freishtat, R. "An evaluation of course evaluations.” ScienceOpen Research 2014. Accessed February 162018. https://www.scienceopen.com/document/vid/42e6aae5-246b-4900-8015dc99b467b6e4?0. doi:10.14293/S2199-1006.1.SOR-EDU.AOFRQA.v1 
Stowell, J.R., Addison, W.E., and Smith, J.L. 2012. “Comparison of online and classroom-based student evaluations of instruction.” Assessment \& Evaluation in Higher Education 37 (4): 465-473. doi:10.1080/02602938.2010.545869

Stroebe, W. 2016. "Why Good Teaching Evaluations May Reward Bad Teaching: On Grade Inflation and Other Unintended Consequences of Student Evaluations.” Perspectives on Psychological Science 11 (6): 800-816. doi:10.1177/1745691616650284

Uttl, B., White, C.A., and Gonzalez, D.W. 2017. “Meta-analysis of faculty’s teaching effectiveness: Student evaluation of teaching ratings and student learning are not related.” Studies in Educational Evaluation 54: 22-42. doi:10.1016/j.stueduc.2016.08.007

Wagner, N., Rieger, M., and Voorvelt, K. 2016. “Gender, ethnicity and teaching evaluations: Evidence from mixed teaching teams.” Economics of Education Review 54: 79-94. doi:10.1016/j.econedurev.2016.06.004

Weinberg, B.A., Hashimoto, M., and Fleisher, B.M. 2009. "Evaluating Teaching in Higher Education.” The Journal of Economic Education 40 (3): 227-261. doi:10.3200/JECE.40.3.227-261

Winchester, M.K., and Winchester, T.M. 2012. "If you build it will they come? Exploring the student perspective of weekly student evaluations of teaching." Assessment \& Evaluation in Higher Education 37 (6): 671-682. doi:10.1080/02602938.2011.563278

Wright, S.L., and Jenkins-Guarnieri, M.A. 2012. "Student evaluations of teaching: combining the meta-analyses and demonstrating further evidence for effective use.” Assessment \& Evaluation in Higher Education 37 (6): 683-699. doi:10.1080/02602938.2011.563279

Youmans, R.J. and Jee, B.D. 2007. “Fudging the Numbers: Distributing Chocolate Influences Student Evaluations of an Undergraduate Course.” Teaching of Psychology 34 (4): 245-247. doi:10.1080/00986280701700318

Zhao, J., and Gallant, D.J. 2012. "Student evaluation of instruction in higher education: exploring issues of validity and reliability.” Assessment \& Evaluation in Higher Education 37 (2): 227-235. doi:10.1080/02602938.2010.523819

7,827 words (excluding reference list, appendix, and ancillary material) 


\section{Appendix: Questionnaire used as the basis for this research}

Section A: About you

Q1. To which school within the university do you currently belong? (tick-box)

Q2. Do you regard yourself as male or female? (tick-box)

Q3. What is your current year and programme? (tick-box)

Section B: About module evaluation

Q4. On a scale of 1-5, how aware were you that a new module evaluation system had been implemented, standardised across the university, as of [two years ago]? (tick-box)

Q5. Please list (in rank order, highest priority first) what aspects of teaching are being evaluated by the current module evaluation questionnaire. (priority ranking)

Q6. To what extent are you aware of changes made as a result of issues addressed on module evaluations? (5-point Likert scale)

Q7. Are you aware of any problems that may have been experienced with implementing or administering standardised module evaluation on your programme? (free-text answer)

Section C: About module evaluation in the context of your programme

Q8. On a scale of 1-5, how effective is the standardised module evaluation form in evaluating the modules on your programme? (5-point Likert scale)

Q9. In your view, what are the advantages of standardised module evaluation? (free-text answer) 
Q10. Are you aware of any disadvantages of standardised module evaluation? (free-text answer)

Q11. On a scale of 1-5, to what extent does standardised module evaluation capture 'local context' e.g. information specific to the department, programme or discipline? (5-point Likert scale)

Q12. In your view, what aspects of this 'local context' are not captured by module evaluation? (free-text answer)

Q13. What point in the module would you consider to be the best time to conduct the module evaluation exercise, and how does this differ from current practice on your programme? (free-text answer)

Section D: About module evaluation and teaching excellence

Q14. On a scale of 1-5, to what extent does module evaluation yield an accurate picture of teaching excellence in your view? (5-point Likert scale)

Q15. If not through module evaluation, in what other way(s) might teaching excellence be recognised? (free-text answer)

Q16. Could the grades awarded in a given module be used to recognise teaching excellence (yes/no), and why? (free-text answer)

Section E: About student surveys at [name of university]

Q17. Approximately how long in total would you estimate that you spend filling out module evaluation surveys per term? (tick-box)

Q18. As a student at [name of university], do you feel that you are undersurveyed, over-surveyed or that the level of surveying is just right? (tickbox) 
Table 1. Student views of standardised module evaluation: breakdown of questionnaire responses.

\begin{tabular}{|c|c|c|c|c|c|c|c|c|c|}
\hline Question & $\begin{array}{c}1 \\
\text { Not at } \\
\text { all }\end{array}$ & $\begin{array}{c}2 \\
\text { Not } \\
\text { much }\end{array}$ & $\begin{array}{c}3 \\
\text { Neutral }\end{array}$ & $\begin{array}{c}4 \\
\text { To some } \\
\text { extent }\end{array}$ & $\begin{array}{c}5 \\
\text { Very } \\
\text { much } \\
\end{array}$ & $\begin{array}{c}\text { No } \\
\text { answer }\end{array}$ & $\begin{array}{l}\text { No. of } \\
\text { respons } \\
\text { es (n) }\end{array}$ & $\begin{array}{c}\text { Mean } \\
\text { average } \\
\text { (1dp) }\end{array}$ & $\begin{array}{c}\text { Standard } \\
\text { deviation } \\
\text { (1dp) }\end{array}$ \\
\hline $\begin{array}{l}\text { Q6. To what extent are you } \\
\text { aware of changes made as a } \\
\text { result of issues addressed on } \\
\text { module evaluations? }\end{array}$ & $\begin{array}{c}7 \\
(18 \%) \\
5 F, 2 M\end{array}$ & $\begin{array}{c}6 \\
(15 \%) \\
3 \mathrm{~F}, 3 \mathrm{M}\end{array}$ & $\begin{array}{c}9 \\
(23 \%) \\
5 \mathrm{~F}, 4 \mathrm{M}\end{array}$ & $\begin{array}{c}13 \\
(33 \%) \\
7 \mathrm{~F}, 6 \mathrm{M}\end{array}$ & $\begin{array}{c}4 \\
(10 \%) \\
4 \mathrm{~F}\end{array}$ & $\begin{array}{c}1 \\
(3 \%) \\
1 \mathrm{U}\end{array}$ & $\begin{array}{c}24 \mathrm{~F} \\
15 \mathrm{M} \\
1 \mathrm{U}\end{array}$ & $\begin{array}{c}3.0 \\
\text { F: } 3.1 \\
\text { M: } 2.9\end{array}$ & $\begin{array}{c}1.3 \\
\text { F: } 1.4 \\
\text { M: } 1.1\end{array}$ \\
\hline $\begin{array}{r}\text { 1st-year undergraduate } \\
\text { 2nd-year undergraduate } \\
\text { 3rd-year undergraduate } \\
\text { Postgraduate taught } \\
\text { Postgraduate research } \\
\text { Other }\end{array}$ & $\begin{array}{c}1 F \\
1 F, 1 M \\
1 F \\
2 F \\
1 M\end{array}$ & $\begin{array}{c}1 M \\
2 F \\
1 F, 2 M\end{array}$ & $\begin{array}{c}1 F, 2 M \\
1 F, 1 M \\
1 F, 1 M \\
2 F\end{array}$ & $\begin{array}{c}2 M \\
2 M \\
5 F, 1 M \\
2 F \\
\\
1 M\end{array}$ & $4 F$ & $1 U$ & $\begin{array}{c}2 F, 5 M \\
8 F, 4 M \\
8 F, 4 M \\
6 F \\
1 M \\
1 M, 1 U\end{array}$ & & \\
\hline $\begin{array}{l}\text { Q8. How effective is the } \\
\text { standardised module } \\
\text { evaluation form in } \\
\text { evaluating the modules on } \\
\text { your programme? }\end{array}$ & $\begin{array}{c}1 \\
(3 \%) \\
1 \mathrm{M}\end{array}$ & $\begin{array}{c}7 \\
(18 \%) \\
5 \mathrm{~F}, 2 \mathrm{M}\end{array}$ & $\begin{array}{c}4 \\
(10 \%) \\
2 \mathrm{~F}, 1 \mathrm{M}, \\
1 \mathrm{U}\end{array}$ & $\begin{array}{c}22 \\
(55 \%) \\
14 \mathrm{~F}, 8 \mathrm{M}\end{array}$ & $\begin{array}{c}4 \\
(10 \%) \\
2 \mathrm{~F}, 2 \mathrm{M}\end{array}$ & $\begin{array}{c}2 \\
(5 \%) \\
1 \mathrm{~F}, 1 \mathrm{M}\end{array}$ & 38 & $\begin{array}{c}3.6 \\
\\
\text { F: } 3.6 \\
\text { M: } 3.6\end{array}$ & $\begin{array}{c}1.0 \\
\text { F: } 0.9 \\
\text { M: } 1.2\end{array}$ \\
\hline $\begin{array}{r}\text { 1st-year undergraduate } \\
\text { 2nd-year undergraduate } \\
\text { 3rd-year undergraduate } \\
\text { Postgraduate taught } \\
\text { Postgraduate research } \\
\text { Other }\end{array}$ & $1 M$ & $\begin{array}{c}2 F, 1 M \\
2 F, 1 M \\
1 F\end{array}$ & $\begin{array}{c}1 F \\
1 F, 1 M\end{array}$ & $\begin{array}{l}2 F, 5 M \\
4 F, 2 M \\
4 F, 1 M \\
\quad 4 F\end{array}$ & $\begin{array}{c}1 F \\
1 F, 1 M \\
1 M\end{array}$ & $\begin{array}{l}1 F \\
1 M\end{array}$ & $\begin{array}{c}\text { As } \\
\text { above }\end{array}$ & & \\
\hline $\begin{array}{l}\text { Q11. To what extent does } \\
\text { standardised module } \\
\text { evaluation capture 'local } \\
\text { context' e.g. information } \\
\text { specific to the department, } \\
\text { programme or discipline? }\end{array}$ & $\begin{array}{c}1 \\
(3 \%) \\
1 \mathrm{~F}\end{array}$ & $\begin{array}{c}9 \\
(23 \%) \\
4 \mathrm{~F}, 4 \mathrm{M}, \\
1 \mathrm{U}\end{array}$ & $\begin{array}{c}13 \\
(33 \%) \\
7 \mathrm{~F}, 6 \mathrm{M}\end{array}$ & $\begin{array}{c}10 \\
(25 \%) \\
9 \mathrm{~F}, 1 \mathrm{M}\end{array}$ & $\begin{array}{c}5 \\
(13 \%) \\
1 \mathrm{~F}, 4 \mathrm{M}\end{array}$ & $\begin{array}{c}2 \\
(5 \%) \\
2 \mathrm{~F}\end{array}$ & 38 & $\begin{array}{c}3.2 \\
\text { F: } 3.2 \\
\text { M: } 3.3\end{array}$ & $\begin{array}{c}1.1 \\
\text { F: } 1.0 \\
\text { M: } 1.2\end{array}$ \\
\hline $\begin{array}{r}\text { 1st-year undergraduate } \\
\text { 2nd-year undergraduate } \\
\text { 3rd-year undergraduate } \\
\text { Postgraduate taught } \\
\text { Postgraduate research } \\
\text { Other }\end{array}$ & $1 F$ & $\begin{array}{l}1 F, 1 M \\
2 F, 3 M \\
\quad 1 F \\
1 U\end{array}$ & $\begin{array}{c}2 F, 2 M \\
1 F, 1 M \\
3 F, 1 M \\
1 F \\
1 M \\
1 M\end{array}$ & $\begin{array}{l}1 M \\
5 F \\
2 F \\
2 F\end{array}$ & $\begin{array}{l}2 M \\
2 M \\
1 F\end{array}$ & $\begin{array}{l}1 F \\
1 F\end{array}$ & $\begin{array}{c}\text { As } \\
\text { above }\end{array}$ & & \\
\hline $\begin{array}{l}\text { Q14. To what extent does } \\
\text { module evaluation yield an } \\
\text { accurate picture of teaching } \\
\text { excellence in your view? }\end{array}$ & $\begin{array}{c}0 \\
(0 \%)\end{array}$ & $\begin{array}{c}9 \\
(23 \%) \\
4 \mathrm{~F}, 5 \mathrm{M}\end{array}$ & $\begin{array}{c}6 \\
(15 \%) \\
5 \mathrm{~F}, 1 \mathrm{M}\end{array}$ & $\begin{array}{c}22 \\
(55 \%) \\
13 \mathrm{~F}, \\
8 \mathrm{M}, 1 \mathrm{U}\end{array}$ & $\begin{array}{c}2 \\
(5 \%) \\
1 \mathrm{~F}, 1 \mathrm{M}\end{array}$ & $\begin{array}{c}1 \\
(3 \%) \\
1 \mathrm{~F}\end{array}$ & 39 & $\begin{array}{c}3.4 \\
\\
\text { F: } 3.5 \\
\text { M: } 3.3\end{array}$ & $\begin{array}{c}\mathbf{0 . 9} \\
\\
\text { F: } 0.8 \\
\text { M: } 1.0\end{array}$ \\
\hline $\begin{array}{r}\text { 1st-year undergraduate } \\
\text { 2nd-year undergraduate } \\
\text { 3rd-year undergraduate } \\
\text { Postgraduate taught } \\
\text { Postgraduate research } \\
\text { Other }\end{array}$ & & $\begin{array}{c}1 F, 4 M \\
1 F, 1 M \\
2 F\end{array}$ & $\begin{array}{l}1 F \\
3 F \\
1 F \\
1 M\end{array}$ & $\begin{array}{c}2 F, 4 M \\
5 F \\
4 F, 3 M \\
2 F \\
\\
1 M, 1 U\end{array}$ & $\begin{array}{l}1 M \\
1 F\end{array}$ & $1 F$ & $\begin{array}{c}\text { As } \\
\text { above }\end{array}$ & & \\
\hline
\end{tabular}

Key: M - Male; F - Female; U - Gender Unspecified 
Table 2. Words per response for each of the free-text questions.

\begin{tabular}{c|c|c|c|c|c|c|c|c}
$\begin{array}{c}\text { Question } \\
\text { (see Appendix) }\end{array}$ & Q7 & Q9 & Q10 & Q12 & Q13 & Q15 & Q16 & Totals \\
\hline $\begin{array}{c}\text { No. of } \\
\text { responses* (n) }\end{array}$ & 22 & 31 & 29 & 20 & 33 & 25 & 34 & 194 \\
Female & 12 & 20 & 16 & 13 & 20 & 14 & 20 & 115 \\
$\begin{array}{c}\text { Male } \\
\text { Unspecified }\end{array}$ & 10 & 10 & 12 & 7 & 12 & 10 & 13 & 74 \\
& & 1 & 1 & - & 1 & 1 & 1 & 5 \\
& & & & & & & & \\
\hline $\begin{array}{c}\text { Total no. of } \\
\text { words }\end{array}$ & 234 & 360 & 464 & 160 & 532 & 250 & 483 & 2483 \\
Female & 103 & 223 & 272 & 62 & 283 & 103 & 269 & 1315 \\
Male & 131 & 124 & 183 & 98 & 241 & 146 & 208 & 1131 \\
Unspecified & - & 13 & 9 & - & 8 & 1 & 6 & 37 \\
\hline $\begin{array}{c}\text { Words/response } \\
\text { (1dp) }\end{array}$ & 10.6 & 11.6 & 16.0 & 8.0 & 16.1 & 10.0 & 14.2 & 12.8 \\
$\begin{array}{c}\text { Female } \\
\text { Male }\end{array}$ & 8.6 & 11.2 & 17.0 & 4.8 & 14.2 & 7.4 & 13.5 & 11.5 \\
Unspecified & - & 13.4 & 15.3 & 14.0 & 20.1 & 14.6 & 16.0 & 15.3 \\
& & & 9 & - & 8 & 1 & 6 & 7.4 \\
& & & & & &
\end{tabular}

* excludes certain answers regarded as non-responses (see main text)

Table 3. Breakdown of responses to Q17 by year of study and gender.

\begin{tabular}{|c|c|c|c|c|}
\hline $\begin{array}{lll}\text { Year } & \text { Response } \\
\end{array}$ & 0-15 minutes & 15-30 minutes & 30-60 minutes & Other \\
\hline $\begin{array}{l}\text { 1st-year undergraduate } \\
\text { 2nd-year undergraduate } \\
\text { 3rd-year undergraduate } \\
\text { Postgraduate taught } \\
\text { Postgraduate research } \\
\text { Other }\end{array}$ & $\begin{array}{c}1 \mathrm{~F}, 4 \mathrm{M} \\
3 \mathrm{~F} \\
6 \mathrm{~F}, 1 \mathrm{M} \\
3 \mathrm{~F}\end{array}$ & $\begin{array}{l}1 \mathrm{M} \\
3 \mathrm{~F}, 1 \mathrm{M} \\
2 \mathrm{~F}, 2 \mathrm{M} \\
\quad 2 \mathrm{~F} \\
1 \mathrm{M}, 1 \mathrm{U}\end{array}$ & $\begin{array}{c}1 \mathrm{~F} \\
2 \mathrm{~F}, 3 \mathrm{M} \\
1 \mathrm{M}\end{array}$ & $\begin{array}{l}1 \mathrm{~F} \\
1 \mathrm{M}\end{array}$ \\
\hline
\end{tabular}

Key: M - Male; F - Female; U - Gender Unspecified 
Table 4. Breakdown of responses to Q18 by year of study and gender.

\begin{tabular}{|l|c|c|c|c|}
\hline Rear & Just right & $\begin{array}{c}\text { Under- } \\
\text { surveyed }\end{array}$ & $\begin{array}{c}\text { Over- } \\
\text { surveyed }\end{array}$ & Other \\
\hline 1st-year undergraduate & $2 \mathrm{~F}, 4 \mathrm{M}$ & & $1 \mathrm{M}$ & \\
2nd-year undergraduate & $6 \mathrm{~F}, 1 \mathrm{M}$ & $1 \mathrm{~F}, 3 \mathrm{M}$ & $1 \mathrm{~F}$ & \\
3rd-year undergraduate & $3 \mathrm{~F}, 2 \mathrm{M}$ & $4 \mathrm{~F}, 2 \mathrm{M}$ & $1 \mathrm{~F}$ & $1 \mathrm{~F}$ \\
Postgraduate taught & $2 \mathrm{~F}$ & $1 \mathrm{~F}$ & $2 \mathrm{~F}$ & $1 \mathrm{M}$ \\
Postgraduate research & & & $1 \mathrm{M}, 1 \mathrm{U}$ & \\
Other & & & & \\
\hline
\end{tabular}

Key: M - Male; F - Female; U - Gender Unspecified 